\title{
Heat stress in older individuals and patients with common chronic diseases
}

\author{
Glen P. Kenny PhD, Jane Yardley MSc, Candice Brown BSc, Ronald J. Sigal MD MPH, Ollie Jay PhD
}

Previously published at www.cmaj.ca

$\mathrm{S}$ cientists have predicted that extremes in climate are likely to increase in frequency and severity. ${ }^{1}$ These changes may have a direct impact on population health, as heat waves can exceed the physiological adaptive capacity of vulnerable population groups. Individuals over the age of 60 years are consistently the most vulnerable, ${ }^{2-4}$ with $82 \%-92 \%$ of excess mortality occurring in this group. ${ }^{5}$ Risks for heat-related illness or injuries are compounded for people with obesity, ${ }^{6,7}$ cardiovascular disease, ${ }^{8-10}$ respiratory disease $^{8-10}$ and diabetes mellitus. ${ }^{4,89}$ These conditions decrease the body's ability to adapt to changes in environmental conditions. ${ }^{11}$ When people must perform physical work in the heat, the occurrence of heat-related morbidity and mortality is likely to be more frequent. ${ }^{12}$ Although these trends in heat-related morbidity and mortality are evident, there has been little research to explain the causes of increased susceptibility within vulnerable populations.

In this review, we describe the effects of heat on human physiology and the factors that increase the risk of heat stress. The methods used in preparing this review are summarized in Box 1 and are described in greater detail in Appendix 1 (available at www.cmaj.ca/cgi/content/full/cmaj.081050 /DC1).

\section{Thermoregulatory responses in healthy people}

In healthy people, the body regulates its core temperature to maintain a near-constant level (about $37^{\circ} \mathrm{C}$ ), irrespective of environmental conditions. To do this, the thermoregulatory system adjusts a variety of physiological mechanisms to attain a balance between the heat produced within the body and the heat lost to the environment, through a combination of dry heat exchange and evaporative heat loss. At room temperature, resting metabolic heat production is balanced primarily by dry heat loss through conduction, convection and radiation. ${ }^{13}$

Heat balance is easily disturbed during exposure to a warmer environment and with changes in metabolic heat production (due to physical activity). As the ambient air temperature increases, the capacity for dry heat exchange is reduced because of a reduction in the temperature gradient between the skin surface and the ambient air. ${ }^{13}$ When the environment

\section{Key points}

- People with age over 60 years, obesity, cardiovascular disease, pulmonary disease or long-standing diabetes are at increased risk of heat-related illness during heat waves because of physiological impairments in the regulation of body core temperature in hot conditions.

- A homebound lifestyle, lack of contact with other people and decreased mobility can also contribute to an increased risk of heat-related illness.

- Working home air conditioners, fans, access to transportation and access to cool environments during prolonged heat events have a protective effect against heat-related illness and deaths.

- Physicians should be aware of these risk factors and protective factors against heat illness, and should counsel at-risk patients accordingly.

is warmer than the skin, the body gains heat through dry heat exchange, which increases the requirements for sweating and circulatory responses to achieve a given rate of heat dissipation. During physical activity, the increase in metabolic rate above resting levels increases the rate at which heat must be dissipated to the environment to prevent the body core temperature from rising to a dangerous level. The extent to which body core temperature increases at steady state is largely independent of the ambient air temperature (within the measured range of $5^{\circ} \mathrm{C}-36^{\circ} \mathrm{C}$ ) and is proportional to the metabolic rate. ${ }^{14}$ With metabolic or environmental heat load or both, the increase in sweat rate and skin blood flow is proportional to the amount of evaporative heat loss required for heat balance. ${ }^{13}$ Under circumstances in which changes in sweating and skin blood flow cannot facilitate a sufficiently high rate of heat loss (e.g., intense physical activity in hot or humid conditions, impairment of normal thermoregulatory function), body core temperature rises continuously; left unchecked, this

From the Human and Environmental Physiology Research Unit (Kenny, Yardley, Brown, Jay), Faculty of Health Sciences, and the Institute of Population Health (Kenny, Yardley), University of Ottawa, Ottawa, Ont.; and the Departments of Medicine, Cardiac Sciences and Community Health Sciences, Faculties of Medicine and Kinesiology (Sigal), University of Calgary, Calgary, Alta.

CMAJ 2009. DOI:10.1503/cmaj.081050 
rise in body core temperature may lead to heat illness and eventually death.

Exposure to the combination of external heat stress and metabolically generated heat can lead to heat-related disorders. The prevalence of heat stress symptoms increases in direct proportion to the elevation of body core temperature. The major heat-related disorders - heat cramps, heat exhaustion and heatstroke - involve various degrees of thermoregulatory failure, which occurs when a person is exposed to excessive heat or elevations in body core temperature over a prolonged period.

\section{Risk factors for heat stress}

\section{Age}

Observational studies have shown that people aged 60 years and older are among the worst affected by extreme heat, ${ }^{3-5}$ with those living in institutions, confined to bed or living alone having the highest rates of illness, injury and death., ${ }^{5,15-17}$ In their ecological time-series study, Fouillet and associates ${ }^{2}$ showed that during the 2003 heat wave in Europe, mortality ratios (ratios of observed deaths to expected deaths) in France increased continuously with age, from 1.3 for people $35-74$ years of age to more than 1.7 for those over the age of 75 (Figure 1). Although the greater prevalence of comorbidities and medication use in this population may be responsible for some of the heat-related deaths, laboratory-based physiological studies have indicated that the ability to sense heat ${ }^{20}$ and to manifest appropriate behavioural (especially fluid intake) ${ }^{21-26}$ and physiological (e.g., blood distribution, sweating) responses ${ }^{27-33}$ during exposure to heat may be compromised in otherwise healthy older individuals.

The ability to physiologically maintain body core temperature during heat stress becomes compromised with age. ${ }^{27}$

\section{Box 1: Review methods}

We searched the following databases for the period January 1924 to February 2009: Ovid Medline, AARP Ageline, AccessScience, Annual Reviews, Cochrane Library, Clinical Evidence, Proquest Dissertations \& Theses Database, EMBASE, HealthSTAR, MEDLINE, Scopus, PASCAL and Scholars Portal. We also used the National Research Council of Canada's National Science Library Catalogue and the Statistics Canada "Health in Canada" website to collect information.

We used the following key words for the search: diabetes, type 1 diabetes, type 2 diabetes, NIDDM, IDDM, heat illness, heat stroke, dehydration, thirst, heat exposure, mortality, morbidity, prevalence, thermoregulation, age, elderly, obesity, fatness, hypertension, cardiovascular disease, lung disease, COPD, high blood pressure, fitness, vulnerable, body heat storage, body temperature, core temperature, socioeconomic status, income, heat wave, education. All searches were limited to humans.

We found no randomized trials evaluating interventions to reduce the risk of heat injury in vulnerable populations. We retained the following types of studies: laboratory-based physiology studies of thermoregulatory function, along with epidemiologic studies, case-control studies and ecological time-series studies showing the vulnerability of specific groups. We excluded case studies.
This decrease in thermoregulatory ability can be attributed to a combination of factors, including changes in sweating, ${ }^{28-30,34}$ blood flow to the $\operatorname{skin}^{30,31,34,35}$ and cardiovascular function. ${ }^{32}$ The problem can be exacerbated by the decreases in overall physical fitness and increases in body adiposity that may accompany aging. ${ }^{36}$ Experts have suggested that, in combination, these age-related changes in thermoregulatory and cardiovascular function can decrease the body's ability to maintain body core temperature at safe levels, especially during extended exposure to heat or to physical activity in the heat. ${ }^{37}$

The results of a recent physiological study ${ }^{20}$ suggested that older people are less sensitive to heat exposure and take longer to respond to temperature changes than their younger counterparts. The age-related decrease in sweat rate does not appear to be due to a decrease in the number of activated sweat glands, ${ }^{28,29}$ but rather to a reduction in the amount of sweat produced per gland, as shown by studies in which the sweat glands were stimulated pharmacologically. ${ }^{28,29,33}$ Older individuals also experience reductions in evaporative heat loss and overall sweat rate during physical activity. ${ }^{27}$

Laboratory-based physiology studies have shown that the reduced sweat output is accompanied by a decrease in skin blood flow during exposure to heat. ${ }^{30,31,34}$ Although the researchers observed no age-related differences in the onset of skin vasodilation, reflex increases in skin blood flow in response to increasing core temperature were attenuated in aged skin during passive heat exposure, independent of the level of acclimation. ${ }^{30}$ Age-related decreases in skin blood flow during passive heat exposure were associated with reduced cardiac output (despite a similar heart rate response) and less redistribution of blood flow from renal and splanchnic circulations. ${ }^{32}$ Similar age-related reductions in skin blood flow have been observed during exercise in the heat. $^{31}$

Older adults may also have a decreased ability to sense and adapt to dehydration. In physiology studies in which dehydration was induced through heat exposure alone, ${ }^{24}$ through physical activity in the heat ${ }^{25,26}$ or through hypertonic saline infusion, ${ }^{23}$ healthy older individuals exhibited lower subjective levels of thirst, decreased plasma volume and reduced water intake while dehydrated relative to younger counterparts. Recovery from dehydration is prolonged in older adults, which may exacerbate their risk of heat-related injuries during extended periods of heat exposure, such as heat waves. ${ }^{21}$

In spite of the apparent thermoregulatory impairments, there is evidence showing that older adults are capable of adapting. ${ }^{30,33}$ Both passive heat exposure and mild to moderate exercise in a very hot environment (i.e., above $40^{\circ} \mathrm{C}$ ) over an 8 - to 10-day period resulted in adaptation in older people. ${ }^{30,33}$ Physiological changes included lower skin and rectal temperatures, increased output of sweat, decreased concentration of sodium in the sweat and a reduced temperature threshold for the onset of vasodilation and sweating..$^{30,33}$ Despite these adaptations, the responses to heat were attenuated after repeated exposure to heat, relative to younger participants undergoing the same acclimation protocol..$^{30,33}$ Whereas physical activity in the heat led to increased thirst, augmented fluid intake and 
greater plasma volume in young individuals, these adaptations may be attenuated in older individuals..$^{21,22}$

\section{Obesity}

Fatal heatstroke occurs 3.5 times more frequently in adults with overweight and obesity than in individuals of average body weight. ${ }^{38}$ Whether this is due to impairments in thermoregula- tion remains essentially unknown, as very few studies have examined heat exposure in obese individuals. Nonetheless, some evidence indicates that both heat-sensing and heatdissipating abilities may be impaired in this population.

Obese individuals may have lower thermal sensitivity to heat stimuli. ${ }^{39}$ The mechanism for this is thought to be related to underlying small-fibre neuropathies, which may in fact be

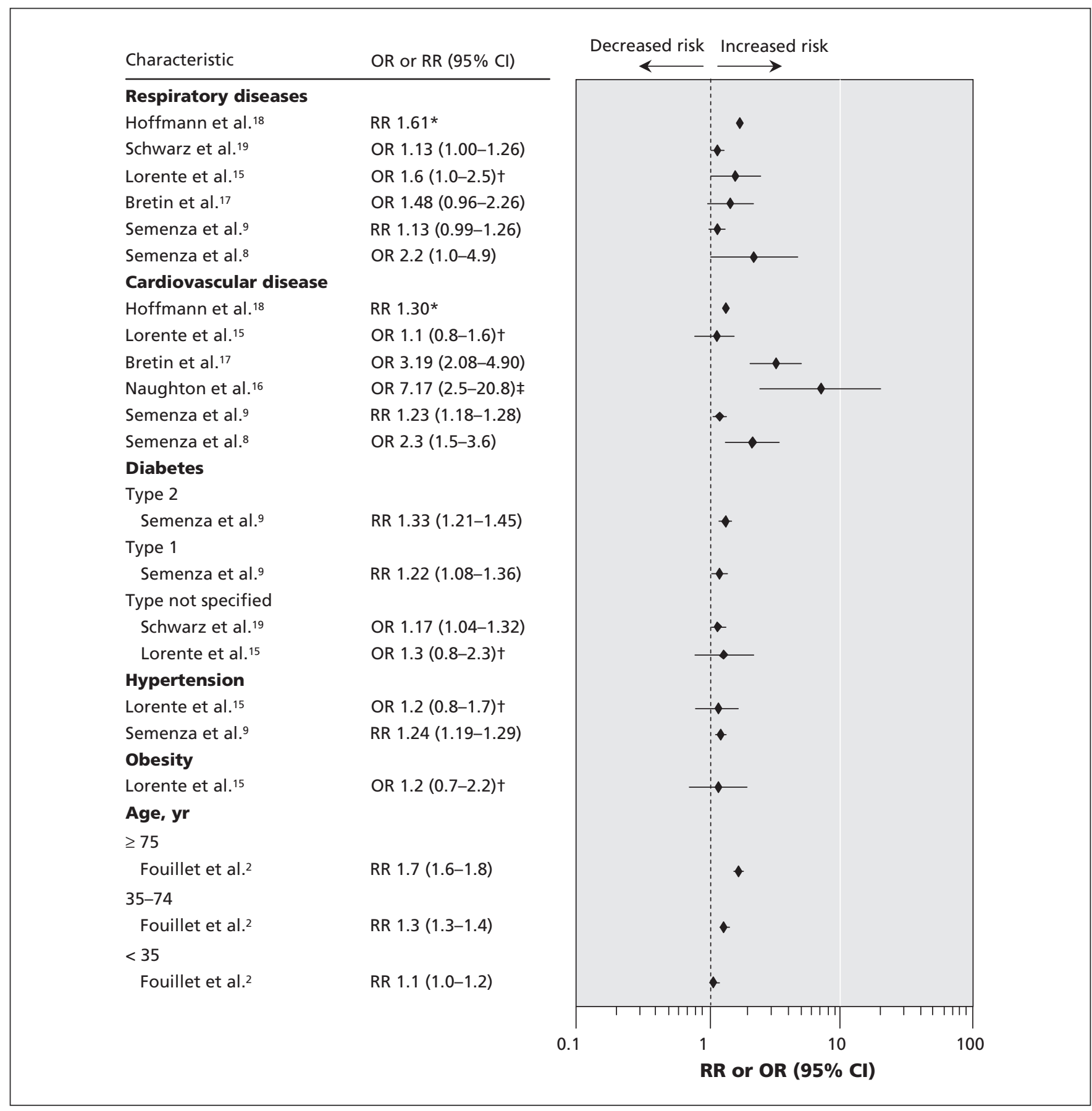

Figure 1: Relative risks (RRs) or odds ratios (ORs) for age and various health conditions. RRs compare hospital admission ${ }^{9}$ or mortality ${ }^{2,18}$ during a heat wave with mortality (or hospital admission) observed during comparison dates without heat wave. ORs compare cases who died during a heat wave with controls in the same geographic area who did not die. Values greater than 1.0 indicate a greater risk of heat-related death or hospital admission. $* 95 \%$ confidence intervals (Cls) were not provided in this study. +Values were adjusted for sex and autonomy (ability to get out of bed, wash and use bathroom without help). $¥$ Values were adjusted for neighbourhood and age. 
common in people with obesity, even in the absence of clinical sensory impairment. ${ }^{39}$ It is unclear, however, if a reduction in thermal sensitivity is associated with a reduction in heat loss effector responses.

A lower capacity for heat dissipation may be responsible for the greater frequency of heat-related injury and illness in this population. ${ }^{38}$ An obese person has a smaller ratio of body surface area to body mass for effective sweat evaporation than a leaner person of the same height, because the greater body mass is not proportional to any difference in the size of the interface for heat exchange with the environment. Furthermore, excess body fat is a liability during exposure to hot environments. The specific heat capacity of adipose tissue is less than that of fat-free mass $\left(2.97 \mathrm{~kJ} \cdot \mathrm{g}^{-1} \cdot{ }^{\circ} \mathrm{C}^{-1} \mathrm{v} .3 .64 \mathrm{~kJ} \cdot \mathrm{g}^{-1} \cdot{ }^{\circ} \mathrm{C}^{-1}\right)$, which means that a given amount of heat storage per unit body mass will cause a greater increase in average tissue temperature in a person with higher body-fat mass. In addition, the thermal conductivity of fatty tissue is lower than that of other tissues in the body. The convective transfer of heat from the body core to the outer shell (the skin) via the circulation is theoretically independent of body fat, since the peripheral blood vessels are located closer to the surface than the subcutaneous fat layers; however, levels of skin blood flow for given elevations in core temperature have been shown to be lower in people with obesity than in those who are not obese. ${ }^{40} \mathrm{~A}$ greater gradient between core and skin temperature develops quickly in a person with obesity, which increases the drive for conductive heat transfer from the body core. However, a thicker subcutaneous layer of adipose tissue restricts this conductive heat transfer and further escalates the risk of heat stress.

The extra weight that obese individuals carry also increases the metabolic cost of weight-bearing activities, which elevates the rate of heat production. As shown by Bar-Or and colleagues, ${ }^{6}$ people with obesity exhibit greater elevation in core temperature than lean individuals for the same absolute workload. This response is independent of ambient temperature and occurs in parallel with elevated sweat rate and greater cardiovascular strain. ${ }^{6}$ The reflex increase in skin blood flow in response to elevated core temperature may also be impaired in obese individuals. ${ }^{40}$

\section{Hypertension}

Hypertension is characterized by elevation of peripheral resistance and is accompanied by a variety of peripheral circulatory changes, including hypertrophy of the vascular smooth muscle $e^{41}$ and vascular rarefaction. ${ }^{42}$ Each of these changes could lead to impairments in the control of blood flow in the skin ${ }^{43}$ and consequently weaken core temperature regulation. During exerciseinduced heat stress, people with hypertension experience an elevated blood pressure response and possibly greater thermal strain than people with normotension. ${ }^{44}$ In earlier studies, Kenney and collaborators ${ }^{44,45}$ found that the increases in forearm blood flow during exercise-induced hyperthermia, which are primarily confined to the skin, ${ }^{46}$ were markedly reduced in people with hypertension relative to people with normotension. This effect could result in a reduction in heat transfer from the body core to the skin, which would increase the potential for heat illness. Whether exercise performed under hot ambient conditions exacerbates this effect remains unclear. It should be noted that the use of antihypertensive medications (diuretics, vasodilators, $\beta$-blockers) may significantly reduce heat tolerance when combined with exercise and warm ambient conditions. ${ }^{47,48}$

The clinical impact of cardiovascular responses during heat exposure in people with hypertension is unknown. Some studies have suggested that thermoregulatory responses to passive heat exposure may in fact be unaltered in people with hypertension. ${ }^{49,50}$ However, the heat exposure in those studies might not have been of sufficient intensity to capture the results of impaired heat loss responses.

\section{Diabetes mellitus}

Epidemiologic data indicate that individuals with diabetes have significantly higher rates of heat illness and death during heat waves than the general population, with excess in-patient admissions being $30 \%$ more numerous (95\% confidence interval $4.6 \%-55.9 \%, p=0.033$; percentages calculated from raw data in published table) during recorded heat waves ${ }^{9}$ (Figure 1). Diabetes is associated with several metabolic, cardiovascular and neurologic dysfunctions, which may also play roles in impairing thermoregulatory mechanisms during heat exposure.

In both type 1 diabetes ${ }^{51}$ and type 2 diabetes, ${ }^{51-53}$ the ability of the blood vessels in the skin to dilate may be impaired, which could decrease the amount of blood being brought to the skin's surface to dissipate heat. When skin blood flow responses were compared in healthy people and people with type 1 and type 2 diabetes (age-matched, ranging from age 18 to 71 years), vascular reactivity was decreased during $5 \mathrm{~min}$ utes of heat exposure among those with diabetes. ${ }^{51}$ Another study showed that the internal temperature at which vasodilation took place during passive whole-body heat exposure was higher for people with type 2 diabetes than for healthy individuals..$^{53}$ The delayed onset of skin vasodilation was due to a delay in the active vasodilatory response, not to an increase in vasoconstrictor activity.

Poor glucose control and the presence of neuropathy may affect sweating responses in individuals with type 2 diabetes. ${ }^{54,55}$ Sweating response during passive heating was impaired in people with type 2 diabetes, especially in the distal regions. ${ }^{54}$ In a separate study, the sweat rate was reduced, especially in the limbs, among people with type 2 diabetes, both at rest and during exercise in the heat.$^{52}$ The lower sweat rate was thought to be associated with diabetes-related peripheral neuropathy and autonomic dysfunction. Sweating responses to pharmacologic stimuli are maintained in individuals with non-neuropathic diabetes but impaired in those with severe neuropathy. ${ }^{55}$ We found no studies that directly measured the impact of these impairments on core temperature during physical exposure to heat or exercise.

Vascular impairments in type 1 diabetes occur with increasing disease duration and greater degrees of hyperglycemia. ${ }^{56,57}$ Using postocclusive hyperemia as a means of observing maximal blood flow, 2 groups of researchers found that participants with diabetes and poor glucose control (i.e., average glycated hemoglobin $>7.5 \%$ ) had poorer blood flow to the limbs than both nondiabetic controls and individuals 
with diabetes who had good glucose control (i.e., average glycated hemoglobin $<7.5 \%){ }^{57,58}$ Similar results were obtained when local heat applied to the foot was used as a stimulus, the participants with diabetes (average glycated hemoglobin $8.7 \%$ ) having lower microvascular dilatation and lower resulting skin blood flow than their nondiabetic counterparts. ${ }^{56}$ Some of these responses may be altered in the presence of high insulin levels. ${ }^{59}$ Whether these decreases in local skin blood flow affect heat delivery to the skin surface and the resultant core temperature response is unknown.

Sweat response can be altered in type 1 diabetes as a result of neuropathy. In a longitudinal study of patients with newly diagnosed type 1 diabetes, the sweat response to a pharmacologic stimulus (acetylcholine) was elevated in the early stages of the disease but decreased with increasing duration of the disease, ${ }^{55,60}$ which would potentially affect the body's ability to maintain core temperature. Differing degrees of sweating impairment during whole-body heat exposure $\left(44^{\circ} \mathrm{C}-50^{\circ} \mathrm{C}\right)$ have been found in people with type 1 diabetes, the loss of sweating response being related to the presence and severity of neuropathy. ${ }^{54}$ There is no direct evidence to indicate how these altered sweat responses affect changes in core temperature during exposure to heat in this population.

Apart from the major cardiovascular and thermoregulatory responses that take place during acute exercise and heat stress, a number of metabolic alterations associated with diabetes may reduce heat tolerance and affect exercise performance in the heat. Early physiological studies suggested that insulin action in type 1 diabetes may be increased by exposure to high temperatures, increasing the risk of hypo-

\begin{tabular}{|c|c|}
\hline Social factor & OR or RR $(95 \% \mathrm{Cl})$ \\
\hline \multicolumn{2}{|c|}{ Access to transportation } \\
\hline Semenza et al. ${ }^{8}$ & OR $0.4(0.2-0.6)$ \\
\hline \multicolumn{2}{|l|}{ Working fan } \\
\hline Naughton et al. ${ }^{16}$ & OR $0.71(0.2-2.3)^{*}$ \\
\hline \multicolumn{2}{|c|}{ Air conditioning use } \\
\hline Semenza et al. ${ }^{8}$ & OR $0.2(0.2-0.4)$ \\
\hline Naughton et al. ${ }^{16}$ & OR $0.2(0.1-0.7)^{*}$ \\
\hline \multicolumn{2}{|l|}{ Ethnic background } \\
\hline \multicolumn{2}{|l|}{ White } \\
\hline O'Neill et al. ${ }^{74}$ & RR 1.04 (1.02-1.06) \\
\hline \multicolumn{2}{|l|}{ Non-white } \\
\hline O'Neill et al. ${ }^{74}$ & RR 1.09 (1.06-1.12) \\
\hline Schwartz et al..$^{19}$ & OR $1.22(1.09-1.37)$ \\
\hline \multicolumn{2}{|l|}{ Education } \\
\hline \multicolumn{2}{|l|}{$>$ high school } \\
\hline O'Neill et al. ${ }^{74}$ & RR 1.01 (0.99-1.02) \\
\hline \multicolumn{2}{|l|}{$\leq$ high school } \\
\hline O’Neill et al.74 & RR 1.05 (1.02-1.09) \\
\hline \multicolumn{2}{|l|}{ Low income } \\
\hline Naughton et al. ${ }^{16}$ & OR $3.1(1.0-9.7)^{*}$ \\
\hline \multicolumn{2}{|l|}{ Living alone } \\
\hline Bretin et al. ${ }^{17}$ & OR $0.59(0.39-0.88)$ \\
\hline Naughton et al. ${ }^{16}$ & OR $8.1(1.4-48.1)^{*}$ \\
\hline Kaiser et al. ${ }^{76}$ & OR 7.6 (0.9-355) \\
\hline Semenza et al. 8 & OR $2.3(1.4-3.5)$ \\
\hline
\end{tabular}

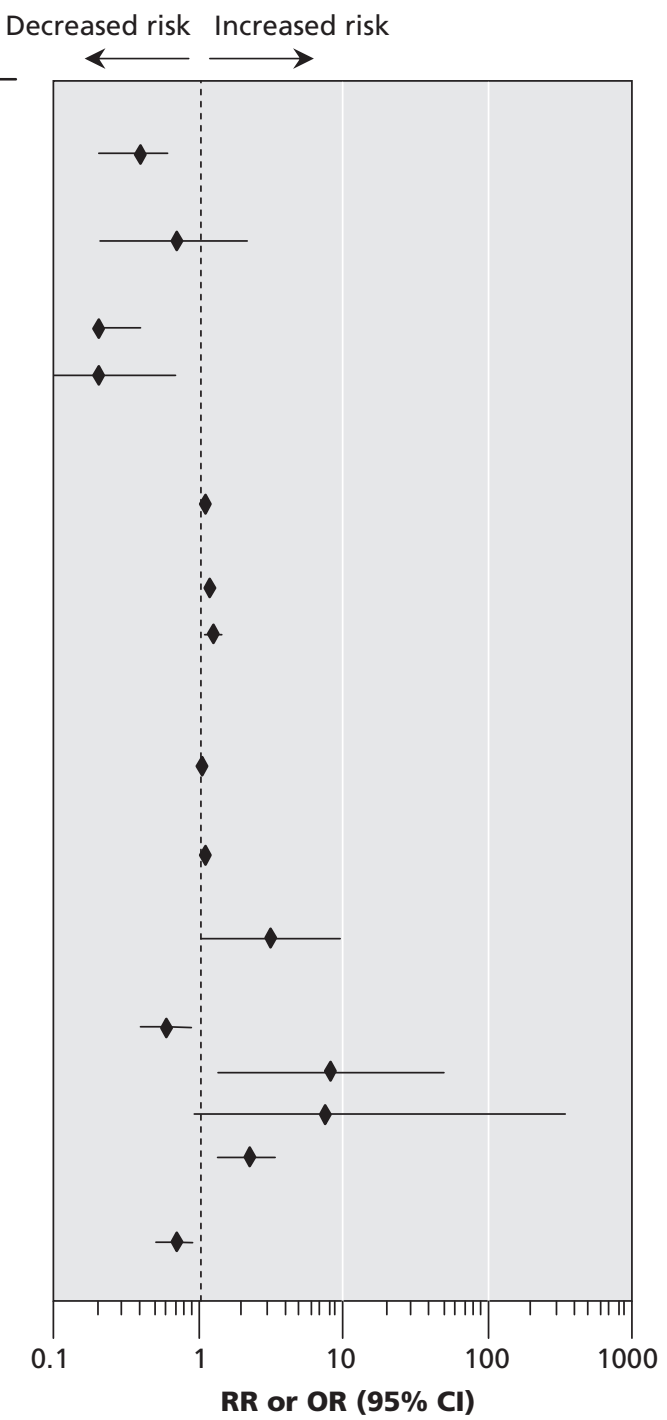

Figure 2: Relative risks (RRs) or odds ratios (ORs) for various social factors. RRs compare mortality during a heat wave with mortality during comparison dates without heat wave. ORs compare cases who died during a heat wave with controls in the same geographic area who did not die. Values greater than 1.0 indicate a greater risk of heat-related death. *Values were adjusted for neighbourhood and age. $\mathrm{Cl}=$ confidence interval. 
glycemia. ${ }^{61,62} \mathrm{We}$ found no studies on this topic examining patients treated with newer forms of insulin or newer insulin delivery systems (i.e., insulin pumps).

\section{Cardiovascular disease}

Cardiovascular disease encompasses heart and circulatory ailments, including coronary and valvular heart disease, chronic heart failure, cardiomyopathy, congenital heart defects, and cerebrovascular and peripheral vascular disease.$^{63}$ Ecological time-series data from the 2003 European heat wave showed that mortality rates among people with cardiovascular disease were $30 \%$ greater during the heat wave than during comparison periods ${ }^{18}$ (Figure 1). Individuals with pre-existing cardiac dysfunction have a reduced ability to increase their cardiac output sufficiently to maintain adequate skin blood flow when core temperature is elevated. ${ }^{64,65}$ If there is long-term exposure to an extreme heat event, stress on the heart and other organs can be exacerbated by dehydration as body core temperature increases. ${ }^{66}$ In healthy individuals, even relatively small decrements in hydration status (1\% of body weight deficit) can impair the cardiovascular and thermoregulatory responses. ${ }^{67}$ Although no studies have directly measured the effect of these impairments on core temperature regulation in individuals with cardiovascular disease, increases in blood viscosity (hemoconcentration) due to dehydration can impose a substantial burden on the cardiovascular system..$^{64,66}$

Heat-related inflammation and coagulation may have contributed to the near doubling of deaths due to cerebral and coronary thrombosis during a London heat wave. ${ }^{66}$ When healthy individuals were exposed to 6 hours of heat (ambient air temperature $41{ }^{\circ} \mathrm{C}$, relative humidity $15 \%-25 \%$ ), blood viscosity increased by $24 \%$, red blood cell count increased by $9 \%$, and platelet count rose by $18 \%$. The authors speculated that in people with vascular disease, in whom vasodilation

\section{Box 2: Suggestions for health care practitioners *}

- Watch for the following risk factors for heat-related illness: age > $60 \mathrm{yr}$, obesity, cardiovascular disease, pulmonary disease, long-standing diabetes mellitus, hypertension, $\dagger$ decreased mobility, homebound lifestyle, homelessness, severe mental illness, poverty.

- Encourage the use of protective measures, including air conditioning, fans, cold showers, transportation to cooler environments and avoidance of strenuous activity in the heat.

- Provide education for patients at risk and their caregivers regarding heat illnesses and their prevention.

- Incorporate a presummer heat-related medical assessment into routine care plans for people with chronic diseases.

- During the session, provide advice about reducing heat exposure, ensuring adequate fluid intake, adjusting medication and other appropriate measures. ${ }^{37}$

- Inform patients about heat response programs in the community.

*For more detailed guidelines, see the World Health Organization publication Heat-health Action Plans, ${ }^{37}$ available online at www.euro.who.int /globalchange/Topics/20080403_2

tThe association with heat-related illness among patients with hypertension may be due to their antihypertensive medications. may be impaired and circulation reduced, such changes might explain the observed increase in thromboses. International experts agree that any factor compromising skin blood flow or normal cardiovascular function (such as a reduction in cardiac output) will augment the risk of heat-related injury and increase the need for careful monitoring. ${ }^{37}$

Unfortunately, very few studies have examined the effects of heat exposure in this population. Those that have been performed have tended to include only participants with relatively mild cardiovascular disease and have therefore likely underestimated the magnitude of the effect in this vulnerable subgroup. Studies of passive heat exposure involving individuals with various cardiovascular impairments have found lower heart rates and lower systolic blood pressure than in healthy controls ${ }^{68,69}$ Cutaneous vasodilation and overall skin blood flow were also impaired, ${ }^{70,71}$ but sweat rate was not affected..$^{69,70}$ In none of these studies were participants required to discontinue use of medications for their conditions (e.g., acetylsalicylic acid, angiotensin-converting-enzyme inhibitors, lipid-lowering medication), which might have confounded their responses to heat exposure. ${ }^{47,48}$

\section{Respiratory disease}

Epidemiologic data indicate that patients with respiratory disease such as asthma, chronic obstructive pulmonary disease, lung cancer, influenza, pneumonia, bronchitis, tuberculosis and cystic fibrosis may be vulnerable to heat exposure ${ }^{8,9}$ (Figure 1). A recent meta-analysis reported that individuals with pulmonary disorders are at a higher risk of death during heat waves (odds ratio 1.61, 95\% confidence interval 1.2-2.1). ${ }^{72}$ There is little evidence to elucidate whether this increase in mortality with heat exposure is due to the changes in air quality that often accompany warmer conditions ${ }^{73}$ or to physiological failures in thermoregulation as a result of chronic conditions. In our literature search, we found no laboratory studies of thermoregulation in people with pulmonary disorders.

\section{Socio-economic considerations}

Ecological time-series and case-control studies of heatrelated mortality have noted an unequal distribution of morbidity and mortality among various socio-economic groups. ${ }^{2,419,74,75}$ A greater risk of mortality due to heat exposure has been associated with lower levels of education, ${ }^{74}$ lower income, ${ }^{16,75}$ being of nonwhite origin ${ }^{4,19,74}$ and social isolation ${ }^{8,16}$ (Figure 2). Working home air conditioners, ${ }^{8,16}$ access to transportation ${ }^{8}$ and access to cool environments during prolonged heat events (e.g., shopping mall, library) ${ }^{8,16}$ have a substantial protective effect against heat-related deaths. Epidemiologic studies have suggested that air conditioning is associated with a relative risk reduction for heat-related illness of about $80 \%$, and the presence of a working fan with a relative risk reduction of about $30 \%$. $^{8.16}$

Housing quality may be a factor affecting the uneven distribution of morbidity and mortality during heat waves. ${ }^{75}$ Those with lower income are more likely to live in crowded or poor-quality housing, where ventilation is inadequate and air conditioning nonexistent. ${ }^{75}$ Homeless people can be especially prone to heat injury through lack of shelter from 
extreme heat or because of underlying chronic physical and psychiatric diseases. ${ }^{4,89,72}$

\section{Future research}

Studies of thermoregulatory function in vulnerable populations have generally been limited to mild heat exposure or have involved low-risk patients. Very few studies have examined physical exertion in the heat involving people with obesity or chronic diseases. There is no information on whether combinations of various factors (e.g., older age and a chronic disease) compound the risk of heat-related morbidity and mortality. It will be essential to discern whether impairment in thermoregulatory capacity exists in terms of the wholebody response and not simply in terms of local heat-loss responses (sweating or skin blood flow or both). New research should focus not only on filling these gaps in the science-based information but also on developing clinical guidelines for health professionals, to facilitate the giving of advice to patients.

\section{Conclusion}

People with age over 60 years, obesity, hypertension, pulmonary or cardiovascular disease, or long-standing diabetes are at increased risk of heat-related illness - heat cramps, heat exhaustion and heatstroke - during prolonged heat events. Other contributing factors include homebound lifestyle, lack of contact with other people and decreased mobility. This increased vulnerability is related to physiologic al impairments in the regulation of body core temperature in hot conditions. Physicians should be aware of these risk factors and of protective factors against heat illness, such as fans, air conditioners and access to cool environments, and should counsel at-risk patients accordingly (Box 2).

\section{This article has been peer reviewed.}

\section{Competing interests: None declared.}

Contributors: Jane Yardley, Glen Kenny and Candice Brown were responsible for selecting the search terms, performing the database searches and assessing study quality. All of the authors were involved in the drafting and revision of the article and approved the final version submitted for publication.

Acknowledgements: This research was supported by Health Canada, Climate Change and Health Office. Jane Yardley was supported by a Canadian Diabetes Association Doctoral Research Award and funds from the Ottawa Health Research Institute Research Chair in Lifestyle Research. Glen Kenny was supported by a University of Ottawa Research Chair Award. Ronald Sigal is supported by a Senior Health Scholar award from the Alberta Heritage Foundation for Medical Research

\section{REFERENCES}

1. United Nations Framework Convention on Climate Change. Report of the Conference of the Parties on its 11th session. Part One: Proceedings; 2005 Nov 28Dec 10; Montréal (QC). Geneva: United Nations; 2006.

2. Fouillet A, Rey G, Laurent F, et al. Excess mortality related to the August 2003 heat wave in France. Int Arch Occup Environ Health 2006;80:16-24.

3. Rey G, Jougla E, Fouillet A, et al. The impact of major heat waves on all-cause and cause-specific mortality in France from 1971 to 2003. Int Arch Occup Environ Health 2007;80:615-26.

4. Ellis FP. Mortality from heat illness and heat-aggravated illness in the United States. Environ Res 1972;5:1-58.

5. Belmin J, Auffray JC, Berbezier C, et al. Level of dependency: a simple marker associated with mortality during the 2003 heatwave among French dependent elderly people living in the community or in institutions. Age Ageing 2007;36:298-303.

6. Bar-Or O, Lundegren HM, Buskirk ER. Heat tolerance of exercising obese and lean women. J Appl Physiol 1969;26:403-9.

7. Havenith G, Coenen JM, Kistemaker L, et al. Relevance of individual characteristics for human heat stress response is dependent on exercise intensity and climate type. Eur J Appl Physiol Occup Physiol 1998;77:231-41.

8. Semenza JC, Rubin CH, Falter KH, et al. Heat-related deaths during the July 1995 heat wave in Chicago. N Engl J Med 1996;335:84-90.

9. Semenza JC, McCullough JE, Flanders WD, et al. Excess hospital admissions during the July 1995 heat wave in Chicago. Am J Prev Med 1999;16:269-77.

10. Ishigami A, Hajat S, Kovats RS, et al. An ecological time-series study of heatrelated mortality in three European cities. Environ Health 2008;7:5.

11. Cooper JK. Preventing heat injury: military versus civilian perspective. Mil Med 1997;162:55-8.

12. Adelakun A, Schwartz E, Blais L. Occupational heat exposure. Appl Occup Environ Hyg 1999; 14:153-4.

13. Gagge A, Gonzalez R. Mechanisms of heat exchange: biophysics and physiology. In: Fregly M, Blatteis C, editors. Experimental physiology. Oxford (UK): Oxford University Press; 1996. p. 45-84.

14. Neilsen M. Die Regulation der Kopertemperatur bei Muskelerbeit. Skand Arch Physiol 1938;79:193-230.

15. Lorente $\mathrm{C}$, Serazin $\mathrm{C}$, Salines $\mathrm{G}$ et al. Étude des facteurs de risque de décès des personnes âgées résidant en établissement durant la vague de chaleur d'août 2003. Paris and Saint-Maurice (France): Ministère de la Santé et des Sports, Direction de la researche des études de l'évaluation et des statistiques; Institut de veille sanitaire; 2005. Available: www.invs.sante.fr/publications/2005/canicule_etablissement /rapport.doc (accessed 2009 May 28)

16. Naughton MP, Henderson A, Mirabelli MC, et al. Heat-related mortality during a 1999 heat wave in Chicago. Am J Prev Med 2002;22:221-7.

17. Bretin $\mathrm{P}$, Vandentorren $\mathrm{S}$, Zeghnoun $\mathrm{A}$, et al. Étude des facteurs de risque de décès des personnes âgées résidant à domicile durant la vague de chaleur d'août 2003. Saint-Maurice (France): Institut de veille sanitaire; 2004. Available: www.invs .sante.fr/publications/2004/chaleur2003_170904/rapport_canicule.pdf (accessed 2009 May 28)

18. Hoffmann B, Hertel S, Boes T, et al. Increased cause-specific mortality associated with 2003 heat wave in Essen, Germany. J Toxicol Environ Health A 2008;71:759-65.

19. Schwartz J. Who is sensitive to extremes of temperature? A case-only analysis Epidemiology 2005;16:67-72.

20. Dufour A, Candas V. Ageing and thermal responses during passive heat exposure: sweating and sensory aspects. Eur J Appl Physiol 2007;100:19-26.

21. Takamata A, Ito T, Yaegashi K, et al. Effect of an exercise-heat acclimation program on body fluid regulatory responses to dehydration in older men. Am J Physiol 1999;277:R1041-50.

22. Zappe DH, Bell GW, Swartzentruber H, et al. Age and regulation of fluid and electrolyte balance during repeated exercise sessions. Am J Physiol 1996;270:R71-9.

23. Phillips PA, Bretherton M, Johnston CI, et al. Reduced osmotic thirst in healthy elderly men. Am J Physiol 1991;261:R166-71.

24. Miescher E, Fortney SM. Responses to dehydration and rehydration during heat exposure in young and older men. Am J Physiol 1989;257:R1050-6.

25. Stachenfeld NS, DiPietro L, Nadel ER, et al. Mechanism of attenuated thirst in aging: role of central volume receptors. Am J Physiol 1997;272:R148-57.

26. Mack GW, Weseman CA, Langhans GW, et al. Body fluid balance in dehydrated healthy older men: thirst and renal osmoregulation. J Appl Physiol 1994;76:1615-23.

27. Inbar O, Morris N, Epstein Y, et al. Comparison of thermoregulatory responses to exercise in dry heat among prepubertal boys, young adults and older males. Exp Physiol 2004;89:691-700

28. Kenney WL, Fowler SR. Methylcholine-activated eccrine sweat gland density and output as a function of age. J Appl Physiol 1988;65:1082-6.

29. Hellon RF, Lind AR. Observations on the activity of sweat glands with special reference to the influence of ageing. $J$ Physiol 1956;133:132-44.

30. Armstrong CG, Kenney WL. Effects of age and acclimation on responses to passive heat exposure. J Appl Physiol 1993;75:2162-7.

31. Kenney WL, Morgan AL, Farquhar WB, et al. Decreased active vasodilator sensitivity in aged skin. Am J Physiol 1997;272:H1609-14.

32. Minson CT, Wladkowski SL, Cardell AF, et al. Age alters the cardiovascular response to direct passive heating. J Appl Physiol 1998;84:1323-32.

33. Inoue Y, Havenith G, Kenney WL, et al. Exercise- and methylcholine-induced sweating responses in older and younger men: effect of heat acclimation and aerobic fitness. Int J Biometeorol 1999;42:210-6.

34. Inoue Y, Shibasaki M, Hirata K, et al. Relationship between skin blood flow and sweating rate, and age related regional differences. Eur J Appl Physiol Occup Physiol 1998;79:17-23.

35. Petrofsky JS, Lohman E 3rd, Suh HJ, et al. The effect of aging on conductive heat exchange in the skin at two environmental temperatures. Med Sci Monit 2006;12: CR400-8.

36. Kenny GP, Yardley JE, Martineau L, et al. Physical work capacity in older adults: implications for the aging worker. Am J Ind Med 2008;51:610-25.

37. Matthies F, Bickler G, Cardeñosa Marín N, et al., editors. Heat-health action plans - guidance (2008). Copenhagen (Denmark): World Health Organization Regional Office for Europe; 2008. Available: www.euro.who.int/globalchange/Topics /20080403_2 (accessed 2009 May 28).

38. Henschel A. Obesity as an occupational hazard. Can J Public Health 1967;58:491-3.

39. Herman RM, Brower JB, Stoddard DG, et al. Prevalence of somatic small fiber neuropathy in obesity. Int J Obes (Lond) 2007;31:226-35. 
40. Vroman NB, Buskirk ER, Hodgson JL. Cardiac output and skin blood flow in lean and obese individuals during exercise in the heat. J Appl Physiol 1983;55:69-74.

41. Folkow B. Physiological aspects of primary hypertension. Physiol Rev 1982;62: 347-504.

42. Greene AS, Tonellato PJ, Lui J, et al. Microvascular rarefaction and tissue vascular resistance in hypertension. Am J Physiol 1989;256:H126-31.

43. Carberry PA, Shepherd AM, Johnson JM. Resting and maximal forearm skin blood flows are reduced in hypertension. Hypertension 1992;20:349-55.

44. Kenney WL, Kamon E, Buskirk ER. Effect of mild essential hypertension on control of forearm blood flow during exercise in the heat. J Appl Physiol 1984;56:930-5.

45. Kenney WL, Kamon E. Comparative physiological responses of normotensive and essentially hypertensive men to exercise in the heat. Eur J Appl Physiol Occup Physiol 1984;52:196-201.

46. Johnson JM, Rowell LB. Forearm skin and muscle vascular responses to prolonged leg exercise in man. J Appl Physiol 1975;39:920-4.

47. Lomax P, Schonbaum E. The effects of drugs on thermoregulation during exposure to hot environments. Prog Brain Res 1998;115:193-204

48. Cheshire WP, Fealey RD. Drug-induced hyperhidrosis and hypohidrosis: incidence, prevention and management. Drug Saf 2008;31:109-26.

49. Drummond PD. Thermoregulatory response to passive body heating in borderline hypertension. Clin Auton Res 1993;3:233-8.

50. Kellogg DL Jr, Morris SR, Rodriguez SB, et al. Thermoregulatory reflexes and cutaneous active vasodilation during heat stress in hypertensive humans. J Appl Physiol 1998;85:175-80.

51. Stansberry KB, Hill MA, Shapiro SA, et al. Impairment of peripheral blood flow responses in diabetes resembles an enhanced aging effect. Diabetes Care 1997; 20:1711-6.

52. Petrofsky JS, Lee S, Patterson C, et al. Sweat production during global heating and during isometric exercise in people with diabetes. Med Sci Monit 2005;11:CR515-21.

53. Wick DE, Roberts SK, Basu A, et al. Delayed threshold for active cutaneous vasodilation in patients with type 2 diabetes mellitus. J Appl Physiol 2006;100:637-41.

54. Fealey RD, Low PA, Thomas JE. Thermoregulatory sweating abnormalities in diabetes mellitus. Mayo Clin Proc 1989;64:617-28.

55. Kihara M, Opfer-Gehrking TL, Low PA. Comparison of directly stimulated with axon-reflex-mediated sudomotor responses in human subjects and in patients with diabetes. Muscle Nerve 1993;16:655-60.

56. Khan F, Elhadd TA, Greene SA, et al. Impaired skin microvascular function in children, adolescents, and young adults with type 1 diabetes. Diabetes Care 2000; 23:215-20.

57. Meyer MF, Schatz H. Influence of metabolic control and duration of disease on microvascular dysfunction in diabetes assessed by laser Doppler anemometry. Exp Clin Endocrinol Diabetes 1998;106:395-403.

58. Golster H, Hyllienmark L, Ledin T, et al. Impaired microvascular function related to poor metabolic control in young patients with diabetes. Clin Physiol Funct Imaging 2005;25:100-5.

59. Bonadonna RC, Saccomani MP, Del Prato S, et al. Role of tissue-specific blood flow and tissue recruitment in insulin-mediated glucose uptake of human skeletal muscle. Circulation 1998;98:234-41.

60. Hoeldtke RD, Bryner KD, Horvath GG, et al. Redistribution of sudomotor responses is an early sign of sympathetic dysfunction in type 1 diabetes. Diabetes 2001;50:436-43.

61. Ronnemaa T, Koivisto VA. Combined effect of exercise and ambient temperature on insulin absorption and postprandial glycemia in type I patients. Diabetes Care 1988;11:769-73.

62. Koivisto VA, Fortney S, Hendler R, et al. A rise in ambient temperature augments insulin absorption in diabetic patients. Metabolism 1981;30:402-5.

63. Brooks GA, Fahey TD, Baldwin KM. Cardiovascular diseases and exercise. In: Exercise physiology: human bioenergetics and its applications. 4th ed. New York (NY): McGraw-Hill; 2005. p. 574-614.

64. Bouchama A, Knochel JP. Heat stroke. N Engl J Med 2002;346:1978-88.

65. Knochel JP, Reed G. Disorders of heat regulation. In: Narins RG, editor. Maxwell \& Kleeman's clinical disorders of fluid and electrolyte metabolism. 5 th ed. New York (NY): McGraw-Hill; 1994. p. 1549-990.

66. Keatinge WR, Coleshaw SR, Easton JC, et al. Increased platelet and red cell counts, blood viscosity, and plasma cholesterol levels during heat stress, and mortality from coronary and cerebral thrombosis. Am J Med 1986;81:795-800.

67. Sawka MN, Montain SJ. Fluid and electrolyte supplementation for exercise heat stress. Am J Clin Nutr 2000;72(Suppl 2):564S-72S.

68. Andersen I, Jensen PL, Junker P, et al. The effects of moderate heat stress on patients with ischemic heart disease. Scand J Work Environ Health 1976;2:256-68.

69. Walsh J, Prpic R, Goodman C, et al. Thermoregulatory responses in post-coronary artery bypass surgery and healthy males during moderate exercise in warm and cool environments. J Cardiopulm Rehabil 2002;22:31-7.
70. Cui J, Arbab-Zadeh A, Prasad A, et al. Effects of heat stress on thermoregulatory responses in congestive heart failure patients. Circulation 2005;112:2286-92.

71. Green DJ, Maiorana AJ, Siong JH, et al. Impaired skin blood flow response to environmental heating in chronic heart failure. Eur Heart $J$ 2006;27:338-43.

72. Bouchama A, Dehbi M, Mohamed G, et al. Prognostic factors in heat wave related deaths: a meta-analysis. Arch Intern Med 2007;167:2170-6.

73. Bélanger D, Berry P, Bouchet V, et al. In: Séguin J, editor. Human health in a changing climate: a Canadian assessment of vulnerabilities and adaptive capacity. Ottawa (ON): Health Canada; 2008. Available: www.sindark.com/NonBlog /Articles/hc-cc-report/CCandHealth.pdf (accessed 2009 May 28).

74. O'Neill MS, Zanobetti A, Schwartz J. Modifiers of the temperature and mortality association in seven US cities. Am J Epidemiol 2003;157:1074-82.

75. Schuman SH. Patterns of urban heat-wave deaths and implications for prevention: data from New York and St. Louis during July, 1966. Environ Res 1972;5:59-75.

76. Kaiser R, Rubin $\mathrm{CH}$, Henderson AK, et al. Heat-related death and mental illness during the 1999 Cincinnati heat wave. Am J Forensic Med Pathol 2001;22:303-7.

\section{Correspondence to: Dr. Glen P. Kenny, School of Human}

Kinetics, University of Ottawa, Montpetit Hall, 125 University

Ave., Ottawa ON K1N 6N5; fax 613 562-5497;

gkenny@uottawa.ca

\section{CMAJ celebrates}

\section{0 years in 2011!} your practice or your life, recollect coincidences, controversies or quirky content..

Send to 100years@cmaj.ca or Carole Corkery, CMAJ, 1867 Alta Vista Dr., Ottawa ON K1G 5W8 